\title{
IMPACT OF PREPAID INCENTIVES IN FACE-TO-FACE SURVEYS: A LARGE-SCALE EXPERIMENT WITH POSTAGE STAMPS
}

\section{Willem Wetzels, Hans Schmeets, Jan van den Brakel, and Remco Feskens}

Nonresponse is a general problem in survey research. Although response rates and the nonresponse trends differ between countries, the general trend is that response rates have been declining over the years (De Leeuw \& De Heer, 2002). A high nonresponse rate is a problem as it reduces the number of respondents and consequently the precision of estimates. In addition, nonresponse can be selective. This occurs when nonrespondents differ systematically from respondents as to the survey objectives. As a result, the survey estimates of the key indicators may be biased. Nonresponse is not only a statistical problem, but it is also a financial problem as declining response rates cause increasing survey costs.

In the nineties, a response rate of 55 percent in face-to-face surveys conducted by Statistics Netherlands was not unusual (De Heer, I999). Due to a substantial reorganization of the fieldwork department and the raise of the minimum number of contact efforts from three to six, the response in Statistics Netherlands' face-to-face surveys gradually increased to 65 percent in 2005 (De Bie \& Luiten, 2005). In order to realize a further increase in the response rate, we decided to focus on the refusals. As Statistics Netherlands does not use a refusal conversion policy-which is a common practice in many other fieldwork organizations, including National Statistical Institutes - we had to consider other measures. One option was the use of incentives. Prepaid cash incentives are known to be most effective, but sending cash by mail is not allowed in the Netherlands. Therefore, postage stamps are chosen as a prepaid incentive, which are expected to be an opportunity to bridge the gap between cash and material incentives. In this article, the effect of stamps as a prepaid incentive in face-to-face surveys on response is tested in a large-scale field experiment embedded in the Dutch Labor Force Survey.

\section{PAST RESEARCH ON THE USE OF INCENTIVES}

The literature shows that incentives can be effective to increase the response rate of surveys. Simmons and Wilmot conclude (2004): 'The general finding from the

The authors thank the referees for careful reading and giving constructive comments on a former draft of the article. The views expressed in this article are those of the authors and do not necessarily reflect the policy of Statistics Netherlands.

This article was first submitted to IfPOR June 27, 2007. The final version was received April 29, 2008. 
literature is that the use of incentives, however small in monetary terms, is effective in increasing response rates in postal, telephone and face-to-face surveys. This seems to be the case for all types of surveys, not just those where there is a high burden for the respondent, and it appears to be true for panel surveys.' In an extensive meta-study Church (I993) shows the significant and positive effect of prepaid incentives on response rates in mail surveys. Church also found that monetary incentives offered with the initial mailing yield higher response rates than material incentives. In the meta-analysis, a strong correlation is also found between the cash value and the effect on the response rate: response rates increase with increasing amounts of money. For mailings in which the incentive was made contingent to returned responses no meaningful increase in response was found. James and Bolstein (I992) examined the effect of monetary incentives in a mail survey. The results indicate that an incentive of \$I significantly increased the response rate, regardless of the number of mailings. The response rate increased also as the incentive was raised from $\$ \mathrm{I}$ to $\$ 5$ and from $\$ 5$ to $\$ 20$. A promise of $\$ 50$ however did not result in a higher response rate over a no-incentive control group. In an earlier article, James and Bolstein (I990) have demonstrated that even very small amounts of money like \$0.25 and \$o.50 do improve the response rate in mail surveys. Dillman (2000) demonstrates that an incentive of $\$ \mathrm{I}$ yields a substantially increased response rate, while an additional increase diminishes as higher amounts $(\$ 2, \$ 3$, etc.) are used.

In a meta-analysis with interviewer-mediated surveys, Singer, Van Hoewyk, Gebler, Raghunathan, and McGonagle (I999) come to comparable conclusions as Church (I993). Paying an incentive is effective in increasing response rates in telephone and face-to-face surveys. In the five studies in the analysis in which a comparison between prepaid and promised incentives could be made, prepayment yielded significantly higher response rates than promised incentives. Another important conclusion is that in interviewer-mediated surveys also gifts are less effective than cash in increasing the response rate, even controlling for the value of the incentive. Singer, Van Hoewyk, and Maher (2000) found that a 5-dollar bill enclosed in an advance letter in a telephone survey had a significant and large effect on the response and cooperation rates.

Groves and Couper (I998) reach the same conclusion: 'The literature shows that incentives appear to increase overall response rates. In both modes of data collection (telephone and personal visit), prepaid incentives lead to increased response rates over no incentives and promised incentives.' For a face-to-face survey with the use of diaries, Nicolaas and Stratford (2005) show a rise in the response rate from $5^{\mathrm{I}}$ to $5^{8}$ percent by using an incentive of 5 pounds, and to $6 \mathrm{I}$ percent for a ro pound incentive. Other studies also demonstrate the positive effect of incentives on response rates (see e.g. Singer, 2002; Teisl, Roe, \& Vayda, 2006).

The effect of prepaid incentives on the response is often explained with the social exchange theory. The potential respondents receive an incentive from the research institution without having to give something back. An incentive is seen as an act of kindness and a token of trust, and this kindness evokes the norm of reciprocity. In accepting the gift, the potential respondent feels obliged by social norms to respond in kind.

Given the literature, a logical choice for face-to-face surveys would be the use of a relatively small cash prepaid incentives. However, sending cash by mail is not 
allowed in the Netherlands. Therefore, we had to use a material incentive and made the choice to use postage stamps. We think incentives like postage stamps provide an opportunity to bridge the gap between cash and material incentives. Postage stamps can be regarded as close to cash, the value is exactly known, and almost everyone uses them more or less frequently.

\section{EXPERIMENTAL DESIGN}

To obtain insight into the effect of prepaid incentives on response rates, their selectivity and costs, we decided to conduct a large-scale experiment embedded in the Labor Force Survey (LFS). The LFS is designed as a rotating panel with five waves. Each month a sample of about 7,500 addresses are drawn by means of stratified twostage sampling. All households on selected addresses, up to a maximum of three households per address, and all household members aged I4 years or over are included in the survey. In the first wave data are collected by computer-assisted personal interviewing (CAPI). The households are re-interviewed four times at quarterly intervals, with data being collected with computer-assisted telephone interviewing (CATI).

The monthly samples of the first wave of November and December 2005 were randomized over four treatment groups with no stamps, 5 stamps, Io stamps, and 20 stamps. In total, 6,960 addresses were approached in November and 6,029 in December. The addresses were allocated over the four treatment groups as:

I. No incentive, 6,195 addresses;

2. Incentive valued 2 euro (5 stamps), 3,I 46 addresses;

3. Incentive valued 4 euro (Io stamps), 3,148 addresses;

4. Incentive valued 8 euro (20 stamps), 500 addresses.

The purpose of this experiment is to investigate the following research questions:

I. What is the effect on the response rates of $2^{-}, 4^{-}$, and 8 -euro incentives?

2. Do incentives improve the selectivity, i.e., decrease the variation in response rates between different subpopulations?

3. Do incentives have any impact on the core indicators in the survey?

Besides the gain in overall response, for the $5^{-}$and Io-stamps versions we were interested in changes in selectivity. A reduction of selectivity would indicate improved quality of the data. This would be of value as the variation of the weights decreases and probably the bias of the estimates of the core indicators would be reduced.

Cost effectiveness is another important factor. Introduction of incentives in faceto-face surveys has to be done preferably without or with very limited extra costs. Berlin et al. (I992) found that offering an incentive can reduce the total survey costs. Simmons and Wilmot (2004) argued that prepaid incentives reduced interviewer effort and consequently at least partially paid for themselves. Whether incentives are cost effective depends on the obtained response increase, the value of the incentive andin case of face-to-face surveys - the average costs of visiting an address. In the case of a fixed number of responses, a 2 euro incentive ( 5 stamps of 39 eurocent each) would 
be cost neutral if the response rate increased by 4 percent; whereas for an introduction of a 4 euro incentive (Io stamps) the response rate would have to go up by 6 percent. In addition to the 2 and 4 euro test groups, a smaller group with 8 euro (20 stamps) was created to determine the additional overall response effect of a larger incentive.

\section{RESULTS}

\section{ResPonse Rates}

A response account of the fieldwork under the four treatment groups of the experiment is given in Table $\mathrm{I}$. The response figures are based on households living alone at an address. Addresses with multiple households are excluded from this analysis because in such cases it is not known which household received the incentive. ${ }^{1}$ The response increases substantially if stamps are included in the advance letter. Compared to the group without incentives, the gain in response rate equals $5.3,7.8$, and 7.4 percent for the groups with 5, Io, and 20 stamps, respectively (according to AAPOR/WAPOR definition No. 2; American Association for Public Opinion Research, 2006). Note that this is caused by lower refusal rates. The percentage of refusals dropped 5.I, 7.I, and I0.I percent, respectively.

A logistic regression analysis reveals that incentives contribute significantly to the response rate. This is true for 5 , Iо, and 20 stamps $(p<$.ог $)$. Also the difference in response rates between the $5^{-}$and Io-stamps group is significant $(p=.04)$. However, due to the small number of households (434), for 20 stamps we can not prove a surplus value in comparison to 5 stamps $(p=.36)$ and io stamps $(p=.88)$.

So far, we discussed the impact of incentives on response rates in the first wave, where data are collected with face-to-face interviews. However, the LFS is designed as a rotating panel with five waves. This raises the question of whether an unconditional small incentive also affects participation in later waves. There are no differences observed in panel attrition between the groups with and without incentives. This indicates that the positive effect of incentives on response rates remains stable in a multi-wave panel design.

\section{Selectivity in Response}

The second research question deals with the selectivity in the response, i.e., will incentives decrease or increase the variation in response rates between different subpopulations?

The LFS is supplemented by administrative data from the Social Statistical Database. In this database, several registers are linked to each other as well as to data from sample surveys. The core of the database is the Population Register. Linking the administrative and survey records to the Population Register, which is also the sample frame of the LFS, makes sociodemographic and socioeconomic information available

\footnotetext{
${ }^{1}$ If we include such cases in the analyses, the figures are very similar. The response rates are slightly lower, except for 20 stamps. No incentive: 64.9 percent, 5 stamps: 70 . I percent, Io stamps: 72.8 percent, 20 stamps: 73.2 percent. The increase for 20 stamps is probably a consequence of the small number of cases (Wetzels \& Schmeets, 2006, p. 7).
} 
TABLE I Response and nonresponse in households by different incentives

\begin{tabular}{|c|c|c|c|c|}
\hline & $\begin{array}{l}\text { No stamps } \\
\text { Count }(\%)\end{array}$ & $\begin{array}{c}5 \text { stamps } \\
\text { Count (\%) }\end{array}$ & $\begin{array}{c}\text { Io stamps } \\
\text { Count (\%) }\end{array}$ & $\begin{array}{c}20 \text { stamps } \\
\text { Count (\%) }\end{array}$ \\
\hline Refusal & I, 2 I I $\quad(23.2)$ & 476 (г8. I) & 432 (I6.I) & $57(\mathrm{I} 3 . \mathrm{I})$ \\
\hline No opportunity & $240(4.6)$ & I25 (4.8) & I23 (4.6) & $26(6.0)$ \\
\hline Language & $78(\mathrm{I} .5)$ & $37(\mathrm{I} .4)$ & 5I (I.9) & $5(\mathrm{I} .2)$ \\
\hline No contact & $262(5.0)$ & I $27(4.8)$ & Io6 $(4.0)$ & $29(6.7)$ \\
\hline Response & $3,4 \mathrm{I9}(65.6)$ & I,865（70.9） & I,964（73.4） & $3 \mathrm{I} 7(73.0)$ \\
\hline Total & $5,210($ (100.0) & 2,630 (100.0) & 2,676 (100.0) & 434 (I00.0) \\
\hline
\end{tabular}

on the respondents and nonrespondents of the LFS at the individual and household level. On the level of individual sampled units, crucial information as age, gender, and ethnicity is available. On the household level, we could use information on household size and household income. We used the standardized household income which is the disposable income corrected for differences in household size and composition. The standardized income is a measure of the prosperity of households.

Response behavior on the personal level was analyzed first since the main parameters of the LFS are defined on the personal level. On the personal level the response rate is slightly higher than on the level of households $(68 . \mathrm{I}, 73.7,75 . \mathrm{I}$, and 76.2 percent for the group with no incentive, 5, Io, and 20 stamps, respectively, compare with Table I). This is caused by a higher response rate among multipleperson households.

The response distributions of the explanatory variables for the four treatments show for most variables only minor effects of the incentives on selectivity. There are, however, effects on the response distributions over regions and country of origin. The influence on response distributions is particularly strong for the three largest cities-Amsterdam, Rotterdam, and The Hague - with the highest nonresponse rates. A Io-stamp incentive results in an increase from 53 to 65 percent, whereas outside of those three cities a moderate increase, from 70 to 76 percent, was obtained.

On the other hand, the sample composition is probably getting worse for the respondent's country of origin. Ethnic minorities constitute about 20 percent of the Dutch population (http://statline.cbs.nl). The ethnic minority or immigrant population is defined in the Netherlands as 'everyone residing in the Netherlands with one or both parents born abroad.' A further distinction is usually drawn between people with one or both parents born in Europe, North America, Australia, Japan, or Indonesia and people from Non-Western countries (mainly Turks, Moroccans, Surinamese, and Antilleans). ${ }^{2}$ The two groups are of approximately the same size. The lower response rate among ethnic minorities is a problem that is not restricted to Statistics Netherlands. Ethnic minorities have lower response rates in almost all the Western countries (Feskens, Hox, Lensvelt-Mulders, \& Schmeets, 2006). We find that incentives do not have an impact on the response rate of the Non-Western ethnic minorities. As a result, incentives increase the response gap between Non-Western

\footnotetext{
${ }^{2}$ For reasons of simplicity we use 'Western foreigners' and 'Non-Western foreigners' in this article.
} 
foreigners and the native Dutch population. This is also true for the gap between the Non-Western and Western foreigners.

The effect of incentives on response behavior is also tested with a logistic regression analysis. Interaction effects between the incentives and the other sociodemographic variables on response rates indicate an increase or decrease of selectivity. Therefore, response behavior ( $\mathrm{I}=$ response; $\mathrm{O}=$ other response categories) is described in a logistic regression model using the following explanatory variables:

- Treatment (no incentive, 5 stamps and 10 stamps)

- Age (15-34/35-44/45-54/55-64/65 and older);

- Gender;

- Household size (1/2/3/4/5 or more members);

- Household income (standardized);

- Region (three largest cities/other areas);

- Country of origin (native Dutch population/Western foreigners/Non-Western foreigners).

As the ro-stamp incentive was the most promising one in terms of an increased response, in particular, for the three largest cities, we started with a model in which the Io-stamp incentive was compared with the no-incentive group. Apart from main effects, we included second order interactions with incentive in the regression model. Two significant interactions are found (a) incentive $x$ region and (b) incentive $\times$ country of origin and are therefore included in the model (Table 2).

Table 2 shows that there is a positive effect from the incentive on response, which indicates that a Io-stamp incentive increases the response. In addition, we find higher response rates of persons belonging to households consisting of more members. A higher income also results in a higher response rate. Furthermore, the $45^{-54}$ agegroup responds less often than the I $^{-34}$ age-group. The difference between response rates of Non-Western foreigners and both Western foreigners and native Dutch population increases due to the incentive. The discrepancy in response between the three largest cities and the other areas is getting smaller. In other words, if we focus on the region, there is less selectivity if we would use a Io-stamp incentive. But, looking at the country of origin indicates an increase in selectivity.

For the 5-stamp incentive it follows that the interaction between region and incentive is no longer significant, whereas the interaction with country of origin remains. Therefore, we conclude that a 5 -stamp incentive does not improve the selectivity of region. For the 20-stamp incentive we find that all interaction effects disappear, very likely due to the small number of cases (results are not presented here).

\section{RESPONSE BIAS}

Two key variables of the LFS are the unemployment rate and the labor force rate. A cross-table shows that there is no correlation between the treatment $(0,5$, Io, and 20 stamps) and the unemployment rate $(p=.7 \mathrm{I})$. Unemployment is 5.6 percent for the group without an incentive and 5.4 percent for 5 stamps and ro stamps (Table 3 ). For the 20 stamps group we found a higher unemployment rate of 6.7 percent. However, this estimate is based on a very small sample (29 cases out of 432 ). 
TABLE 2 Logistic regression: incentive treatment $(5$ versus o stamps and Io versus o stamps) and sociodemographic characteristics on response (no/yes)

\begin{tabular}{|c|c|c|c|c|c|c|c|c|c|c|}
\hline & \multicolumn{5}{|c|}{5 versus o stamps } & \multicolumn{5}{|c|}{ Iо versus o stamps } \\
\hline & $B$ & $S E$ & Wald & $d f$ & Sig. & $B$ & $S E$ & Wald & $d f$ & Sig. \\
\hline Treatment & 0.443 & O.I 57 & 8.0 & I & .005 & 0.775 & O.I 58 & $23 \cdot 9$ & I & .000 \\
\hline $\begin{array}{l}\text { Household size } \\
\text { I person (ref. cat.) }\end{array}$ & & & 93.6 & 4 & .000 & & & 6I.I & 4 & .000 \\
\hline 2 persons & 0.385 & 0.066 & 33.6 & I & .000 & 0.327 & 0.067 & 23.9 & I & .000 \\
\hline 3 persons & $0.5 \mathrm{I} 3$ & 0.080 & $4 \mathrm{I} \cdot 5$ & I & .000 & 0.397 & 0.079 & 25.0 & I & .000 \\
\hline 4 persons & 0.596 & 0.080 & 55.0 & I & .000 & 0.522 & $0.08 \mathrm{I}$ & 4I.8 & I & .000 \\
\hline 5 or more persons & 0.827 & o.1o6 & 61.0 & I & .000 & 0.6 I 8 & 0.104 & $35 \cdot 3$ & I & .000 \\
\hline Income household & 0.127 & 0.027 & $2 \mathrm{I} .8$ & I & .000 & $0 . \mathrm{I} 2 \mathrm{I}$ & 0.027 & 20.2 & I & .000 \\
\hline $\begin{array}{l}\text { Age } \\
\text { I } 5-34 \text { years } \\
\text { (ref. cat.) }\end{array}$ & & & I 6.5 & 4 & .002 & & & 9.8 & 4 & .045 \\
\hline $35-44$ years & -0.135 & 0.078 & 3.0 & I & .084 & - O.IOI & 0.079 & I.7 & I & .197 \\
\hline $45^{-54}$ years & -0.187 & 0.079 & $5 \cdot 6$ & I & .018 & $-0 . \mathrm{I} 8 \mathrm{I}$ & 0.079 & $5 \cdot 3$ & I & $.02 \mathrm{I}$ \\
\hline $55^{-64}$ years & 0.097 & 0.080 & I. 5 & I & .228 & 0.039 & $0.08 \mathrm{I}$ & 0.2 & I & .628 \\
\hline 65 years and older & 0.037 & 0.095 & O.I & I & .700 & -0.076 & 0.096 & 0.6 & I & .426 \\
\hline $\begin{array}{l}\text { Country of origin } \\
\text { Native Dutch } \\
\text { population } \\
\text { (ref. cat.) }\end{array}$ & & & 7.2 & 2 & .028 & & & $7 \cdot 3$ & 2 & .027 \\
\hline Western foreigners & -0.233 & 0.103 & $5 \cdot \mathrm{I}$ & I & .023 & -0.235 & 0.102 & $5 \cdot 3$ & I & $.02 \mathrm{I}$ \\
\hline $\begin{array}{l}\text { Non-Western } \\
\text { foreigners }\end{array}$ & -0.187 & O.II3 & 2.7 & I & .098 & -0.184 & O.II3 & 2.7 & I & .102 \\
\hline Region & $0.64 \mathrm{I}$ & 0.094 & 46.3 & I & .000 & $0.66 \mathrm{I}$ & 0.094 & $49 \cdot 4$ & I & .000 \\
\hline Region by Treatment & -0.164 & 0.162 & I.O & I & $\cdot 3$ I I & -0.364 & 0.162 & 5.0 & I & .025 \\
\hline $\begin{array}{l}\text { Country of } \\
\text { origin } \times \text { Treatment }\end{array}$ & & & 9.0 & 2 & .OI I & & & II.O & 2 & .004 \\
\hline $\begin{array}{c}\text { Western foreigners } \\
\text { by Treatment }\end{array}$ & O. I I 7 & O. I 88 & 0.4 & I & .532 & -0.084 & o. 178 & 0.2 & I & .635 \\
\hline $\begin{array}{l}\text { Non-Western } \\
\text { foreigners by } \\
\text { Treatment }\end{array}$ & $-0.54 \mathrm{I}$ & 0.190 & 8. I & I & .004 & $-0.62 \mathrm{I}$ & O.I 87 & I I.O & $\mathbf{I}$ & $.00 \mathrm{I}$ \\
\hline Constant & $-0.2 \mathrm{I} 4$ & o. 108 & 3.9 & I & .048 & -0.148 & о. 108 & I.9 & I &. $\mathrm{I} 7 \mathrm{I}$ \\
\hline
\end{tabular}

TABLE 3 Unemployment rate and labor force by incentive treatments

\begin{tabular}{lcccc}
\hline & No stamps & 5 stamps & Io stamps & 20 stamps \\
& Count $(\%)$ & Count $(\%)$ & Count (\%) & Count (\%) \\
\hline $\begin{array}{l}\text { Unemployment rate } \\
\text { Labor force }\end{array}$ & $257(5.6)$ & I35 (5.4) & I $45(5.4)$ & $29(6.7)$ \\
& $4,598(67.7)$ & 2,5 I $8(68.7)$ & $2,682(69.4)$ & $432(68.7)$ \\
\hline
\end{tabular}


The labor force rate varies between 67.7 percent (no incentives) and 69.4 percent ( Io stamps). There is obviously no correlation between the labor force rate and the treatment ( $p=.29$ based on a Chi-squared test for independency). In addition, the effect of the incentive treatments on the unemployment rate and the labor force rate is tested in a logistic regression model with age, gender, household composition, standardized income, region, and country of origin as covariates. No effects were found of the incentive treatment on the unemployment rate, neither main effects nor interaction effects. The same holds for the labor force.

\section{CONCLUSIONS AND DISCUSSION}

The experiment clearly demonstrates that including postal stamps with the advance letter results in a substantial increase of response. Compared with the response rate of 65 percent in the control group, a 5 -stamp incentive ( 2 euro) increased the response by 5 percent, a Io-stamp incentive (4 euro) resulted in an 8 percent higher response rate, and a 20-stamp incentive ( 8 euro) in a 7 percent response raise. As expected this was caused by a decrease of the refusals. The refusal rate of 23 percent in the control group declined by 5, 7, and io percent, respectively. These figures show that, in a face-to-face survey, postal stamps included with the advance letter persuade potential refusers to participate and that there is a strong correlation between the value of the incentive and the decrease of the refusals. This result supports our assumption that stamps are perceived similar to money incentives. In situations where sending cash by mail is not allowed or giving cash is seen as not appropriate, stamps can be a good alternative to cash incentives. It appears that stamps provide an opportunity to bridge the gap between cash and material incentives.

On the other hand, incentives do not seem to improve selectivity. Although the sample size is quite large, there is hardly any impact on the response distributions over the different subpopulations. This implies that the additional group of respondents participating in the survey does not differ in their sociodemographical composition compared to the group of respondents that is reached without offering an incentive. There are two exceptions. First, the response rate of Non-Western foreigners is not increased with a 5 or Io stamp incentive. Second, the differences in response rates between regions decreases, since the response rate in the three largest cities of the country increases stronger than in other areas when a Io-stamp incentive is given.

Finally, the incentives hardly changed the key characteristics in the LFS. If small unconditional incentives, in our case stamps, do not have an impact on the key characteristics, why should Statistics Netherlands change its policy into submitting incentives? We think this study is not sufficient to provide a clear answer. It is our belief that more research is necessary to determine the effects of incentives on selectivity as well as on response bias. We nevertheless think that the increases in response rates are substantial and encouraging. This is very promising, all the more, as our experiment shows, the use of small unconditional incentives can be done cost-neutral or may even reduce the total survey costs. 


\section{REFERENCES}

The American Association for Public Opinion Research. (2006). Standard definitions: Final dispositions of case codes and outcome rates for surveys (4th ed.). Lenexa, KS: AAPOR.

Berlin, M., Mohadjer, L., Waksberg, J., Kolstad, A., Kirsch, I., Rock, D., et al. (1992). An experiment in monetary incentives. Proceedings of the Survey Research Section of the American Statistical Association, 393-398, (http://www.amstat.org/ sections/srms/proceedings/y1992f.html).

Church, A. H. (I993). Estimating the effect of incentives on mail survey response rates: A meta-analysis. Public Opinion Quarterly, 57, 62-79.

De Bie, S., \& Luiten, A. (2005). Lifting response rates: Part Tmo. Paper presented at the I6th International Workshop on Household Survey Nonresponse. Sweden: Tälberg.

De Heer, W. (I999). International response trends: Results of an international survey. Fournal of Official Statistics, 15, I29-I42.

De Leeuw, E., \& De Heer, W. (2002). Trends in household survey nonresponse: A longitudinal and international comparison. In R. M. Groves, D. A. Dillman, J. L. Eltinge, \& R. J. A. Little (Eds.), Survey nonresponse (pp. 4I-54). New York: Wiley.

Dillman, D. A. (2000). Mail and internet surveys. New York: Wiley.

Feskens, R. C. W., Hox, J., Lensvelt-Mulders, G., \& Schmeets, H. (2006). Collecting data among ethnic minorities in an international perspective. Field Methods, I8, 284-304.

Groves, R. M., \& Couper, M. P. (I998). Nonresponse in household interviem surveys. New York: Wiley.

James, J. M., \& Bolstein, R. (I990). The effect of monetary incentives and follow-up mailings on the response rate and response quality in mail surveys. Public Opinion Quarterly, 54, 346-36r.

James, J. M., \& Bolstein, R. (I992). Large monetary incentives and their effect on mail survey response rates. Public Opinion Quarterly, 56, 442-453.

Nicolaas, G., \& Stratford, N. (2005). A plea for the tailored use of respondent incentives. In C. van Dijkum, J. Blasius, \& C. Durand (Eds.), Recent developments and applications in social research methodology (CD-ROM of the RC33 Sixth International Conference on Social Science Methodology, Workshop No. 32 I, pp. I-I5). Amsterdam: Budrich.

Simmons, E., \& Wilmot, A. (2004). Incentive payments on social surveys: A literature review. Survey Methodology Bulletin, 53,(I) I-2.

Singer, E. (2002). The use of incentives to reduce nonresponse in household surveys. In R. M. Groves, D. A. Dillman, J. L. Eltinge, \& R. J. A. Little (Eds.), Survey nonresponse (pp. I63-I78). New York: Wiley.

Singer, E., Van Hoewyk, J., Gebler, N., Raghunathan, T., \& McGonagle, K. (I999). The effect of incentives on response rates in interviewer-mediated surveys. Fournal of Official Statistics, 15, 217-230.

Singer, E., Van Hoewyk, J., \& Maher, M. (2000). Experiments with incentives in telephone surveys. Public Opinion Quarterly, 64, I7 I-I 88. 
Teisl, M. F., Roe, B., \& Vayda, M. E. (2006). Incentive effects on response rates, data quality, and survey administration costs. International fournal of Public Opinion Research, I8, 364-373.

Wetzels, W., \& Schmeets, H. (2006). Tmeede adviesnota 'Experiment Postzegel Beloning' [Second advisory report on 'Experiment Postage Stamps']. CBS-rapport SOO-2006-Hı 4 /intern. Heerlen: Statistics Netherlands.

\section{BIOGRAPHICAL NOTES}

Willem Wetzels is researcher at Statistics Netherlands (Division of Social and Spatial Statistics, Heerlen). His current research focuses on the research on and implementation of data collection methods, mixed mode survey, the reduction of nonresponse, and difficult-to-survey groups.

Hans Schmeets is senior researcher at Statistics Netherlands (Division of Social and Spatial Statistics, Heerlen) and professor at Maastricht University (Faculty of Arts and Social Sciences, Department of Political Studies). His main research interests are various aspects of the quality of life, social cohesion, elections, and survey methodology. He has a long-standing work relation with international organizations in the field of democratization, in particular, the Organization for Security and Cooperation in Europe (OSCE).

Jan van den Brakel is a senior statistician at Statistics Netherlands (Division of Methodology and Quality). His research interests include design and analysis of experiments embedded in complex sample surveys, survey sampling, small area estimation, and time series analysis. He published papers in the Fournal of Official Statistics, Metron, Survey Methodology, Research in Official Statistics, Statistics in Transition and the European Journal of Survey Research Methods.

Remco Feskens is a $\mathrm{PhD}$ student in methods and statistics at Utrecht University, the Netherlands. His main research interests are survey methodology and issues of survey data quality. His current research projects are difficult-to-survey groups and reduction of nonresponse rates and nonresponse bias.

Address correspondence to Willem Wetzels, Statistics Netherlands, Division of Social and Spatial Statistics, P.O. Box 448I, 640 ICZ Heerlen, The Netherlands, e-mail: wwts@cbs.nl 